\title{
The deadly effects of "nonlethal" predators
}

\author{
Shannon J. McCauley, ${ }^{1}$ Locke Rowe, and Marie-Josée Fortin \\ Ecology and Evolutionary Biology, University of Toronto, 25 Willcocks Street, Toronto, Ontario M5S3B2 Canada
}

\begin{abstract}
Nonconsumptive predator effects are widespread and include plasticity as well as general stress responses. Caged predators are often used to estimate nonconsumptive effects, and numerous studies have focused on the larval stages of animals with complex life cycles. However, few of these studies test whether nonconsumptive predator effects, including stress responses, are exclusively sublethal. Nor have they assessed whether these effects extend beyond the larval stage, affecting success during stressful life-history transitions such as metamorphosis. We conducted experiments with larvae of a dragonfly (Leucorrhinia intacta) that exhibits predator-induced plasticity to assess whether the mere presence of predators affects larval survivorship, metamorphosis, and adult body size. Larvae exposed to caged predators with no ability to attack them had higher levels of mortality. In the second experiment, larvae reared with caged predators had higher rates of metamorphic failure, but there was no effect on adult body size. Our results suggest that stress responses induced by exposure to predator cues increase the vulnerability of prey to other mortality factors, and that mere exposure to predators can result in significant increases in mortality.
\end{abstract}

Key words: caged predator; dragonfly larvae; Leucorrhinia intacta; metamorphosis; nonconsumptive predator effects; predation; predator-induced stress response; stress effects.

\section{INTRODUCTION}

Predators impact prey populations and their communities through both direct consumptive and indirect nonconsumptive effects (NCEs; Preisser et al. 2005, Preisser and Bolnick 2008). Prey responses to predators include plastic changes in behavior, physiology, and morphology, that, while reducing predation risk, may also result in slower growth and development (Benard 2004), reduced fecundity (Preisser et al. 2005), and, in some situations, greater risk of mortality from other sources (Kotler et al. 1993). Predator-induced phenotypic prey responses consequently affect population dynamics, and in turn, community structure (Werner and Peacor 2003, Preisser et al. 2005, Preisser and Bolnick 2008).

Prey responses to predators include hormonal stress responses that are not necessarily adaptive (Fraker 2009, Preisser 2009, Sheriff et al. 2009). In animals, neuroendocrine stress responses are a near-universal reaction to perception of predation risk (Hawlena and Schmitz 2010). These stress responses may be a major component of the negative impact of predators on prey, and their analysis can provide insights into how stress more generally affects populations, communities, and even ecosystem-level processes (Preisser 2009, Hawlena and Schmitz 2010). For example, because many anthropo-

Manuscript received 8 March 2011; revised 24 June 2011; accepted 29 June 2011. Corresponding Editor: K. O. Winemiller.

${ }^{1}$ Present address: Department of Biological Sciences, California Polytechnic State University, San Luis Obispo, California 93407-0401 USA. E-mail: smccauley@calpoly.edu genic environmental changes impose stress on those individuals that do not experience direct mortality, linking these impacts to predator-induced changes in prey performance should provide insights for interpreting and predicting demographic response (Sheriff et al. 2009).

Studies of the nonconsumptive effects of predators on prey have primarily focused on the costs of adaptive plasticity or nonlethal stress effects. However, there are hints that stress itself can increase mortality. For example, Stoks (2001) found that larval damselflies exposed to caged invertebrate predators had marginally $(P=0.06)$ higher mortality than larvae without predator exposure. If predator-induced stress responses have direct mortality effects, this would be an especially extreme nonconsumptive effect, and one with important implications for both predator-prey dynamics and for analysis of experiments on NCEs. Analyses of NCE experiments either may not account for this mortality or may misattribute the mechanism causing it, thus leading to misinterpretation. For example, even small changes in prey densities from nonconsumptive predator mortality might decrease the ability to detect the sublethal effects of predators in caged predator trials, particularly when focal metrics (e.g., growth rates) are highly density dependent. Impacts of predators that are caged or otherwise rendered "nonlethal" to prey typically are assumed to operate through mechanisms unrelated to density, and therefore density effects are frequently not assessed.

Organisms experience acute stress during certain lifehistory events (e.g., reproduction, migration, metamorphosis), and nonconsumptive effects of predators should 
be greatest during these periods. Metamorphosis itself induces stress responses (Heyland and Moroz 2006, Menon and Roman 2007), and organisms with complex life cycles have been the subject of a large number of studies on NCEs (Benard 2004). Despite this, most of these studies examine NCEs only within the larval phase, and do not follow organisms through to the adult stage to assess the consequences of prior predator exposure at this key point of life-history transition (but see Relyea 2001, Stoks 2001, Benard and Fordyce 2003, Stamper et al. 2009). Determining whether larval exposure to predators induces carryover effects between life-history stages, either in terms of metamorphic success or adult phenotype, is essential to understanding the full consequences of nonconsumptive predator effects for organisms with complex life cycles.

We used two experiments to investigate the effects of two levels of predator-induced stress on nonconsumptive prey mortality. In both of these studies, our prey species was the dragonfly Leucorrhinia intacta, which exhibits phenotypic plasticity in response to the presence of predatory fish (McCauley et al. 2008). In the second of our two experiments, we followed the effects of a nonlethal predator across a stressful life-history stage, metamorphosis, so that we could assess whether nonconsumptive predators had particularly strong effects at this transition and whether there were carryover effects for adults.

\section{Methods}

\section{Study system}

In the region where both experiments were conducted the flight season for Leucorrhinia intacta runs between May and early July, and emergence from the larval stage occurs across this period. Eggs hatch during mid- to late summer, typically $3-4$ weeks after being laid, and larvae grow through the next 10 months prior to emerging into the adult stage the following year.

\section{Experiment 1: Effects of predator exposure on larval mortality at high predator densities}

Larval L. intacta (individuals were in instars 4-5) were collected from two water-bodies in southeast Michigan (USA), one in which fish were the top predators and a fishless pond in which invertebrates were the top predators. Groups of three larvae from a given source pond were assigned in a stratified random fashion to cages in experimental aquaria so that each aquarium had a total of four cages, two from each source.

There were three treatments: fish (Lepomis macrochirus) present, invertebrate predator (Anax junius) present, or no predator. Each treatment was replicated eight times. Replicates consisted of 75-L aquaria filled with well water within which were suspended four mesh cages containing larval L. intacta; the predator could not enter the cages but was able to move freely within aquaria. Each predator-treatment aquarium had a single predator. Each mesh cage had a small plastic cup inside, weighted to the bottom with gravel, to allow dragonflies to hide from sight of predators.

Dragonfly larvae were fed zooplankton (a mixture of taxa dominated by Daphnia spp. but also including a smaller number of copepods) ad libitum $(\sim 120-150$ zooplankton per feeding) three times per week; enough zooplankton persisted between feedings such that food was consistently available to larvae. Predators were fed two L. intacta larvae three times per week. A randomly selected subset of cages were sampled at two time points in the experiment (27 August and 29 September), and the head widths of all larvae within each cage were measured using digital calipers (accurate to \pm 0.001 $\mathrm{mm})$. The experiment began on 7 August 2001 and ended on 2 October 2001 when surviving larvae were removed from their mesh cages, counted, and preserved in $70 \%$ ethanol. This experiment encompassed $\sim 20 \%$ of the larval period which typically extends through the winter months. Studies of larvae of other odonate species in northern temperate lakes have revealed that growth rates decline substantially during winter (De Block et al. 2007).

\section{Experiment 2: Effects of predator exposure on larval mortality, metamorphic success, and adult morphology at low predator density}

Larval L. intacta were collected from two sites on the Koffler Scientific Reserve (Ontario, Canada), a pair of adjacent ponds that had fish as top predators and a fishless pond. Larvae from both sites were instars at stages 7-9. This experiment covered the latter portion of the larval period. Larvae were kept in holding tanks, one for each source type, for 3-4 days prior to placing them in experimental tanks. Larvae were collected from their respective holding tanks and divided into groups of five larvae each that were then randomly assigned to experimental tanks until each tank had 40 individuals from a given source type (fish or fishless). The experiment had two treatments: fish predators (Lepomis gibbosus) or no predator. Fish were fed a mix of frozen plankton and earthworms daily throughout the experiment. Each treatment $\times$ source combination was replicated five times.

Experimental units were 378-L cattle-watering tanks filled with filtered pond water and containing a cage that held either a single fish or no fish. Prior to beginning the experiment, each tank received an initial inoculum of zooplankton (Daphnia spp. and copepods), which established abundant populations of zooplankton. In this experiment we reared individual dragonfly larvae to the adult stage. Therefore, each tank was covered by a mesh mosquito net sealed to the edge of the tank that prevented emergent adults from escaping.

Larvae were housed in the experimental tanks until they either completed metamorphosis and emerged into the adult stage or died. Tanks and their associated nets were checked daily 1-3 times per day depending on the 
weather (emergence is more common on warm sunny days than cool, rainy ones, and tents were checked 2-3 times on sunny days and only once in the morning on rainy days). Live adults and those adults that had emerged successfully but then died (typically by drowning) were placed in mesh cages and held in cool conditions overnight to allow them to fully harden before handling. We also recorded the presence of individuals that failed to successfully complete metamorphosis, dying before completely breaking free of the larval exoskeleton. The experiment began on 26 May 2009 and terminated on 17 July 2009, with the final emergence event occurring on 4 July 2009. Adult specimens were sexed and head width, thorax length, and forewing length were measured using calipers (accurate to $\pm 0.001 \mathrm{~mm}$ ). These measures were combined in a principal-components analysis using the correlation matrix to derive a single metric of body size. Factor scores from this analysis were saved for each individual and these values were used in all subsequent analyses. A Shapiro-Wilk test was used to assess whether body sizes were normally distributed in each treatment. The effects of predator treatment on body size were compared using a nested general linear model (GLM) with tank nested within treatment and no post hoc tests were used because only two treatments were compared. All analyses were conducted using SPSS version 17 (SPSS 2008).

\section{RESULTS}

Experiment 1: Effects of predator exposure on larval mortality at high predator densities

There was no significant interaction between treatment and source (GLM: $F_{2,42}=0.56, P=0.575$ ). Consequently, we compared the mean survival rate in each tank between treatments. Treatment had a significant effect on larval survival $\left(F_{2,21}=31.5, P<\right.$ 0.001; Fig. 1): survival was significantly lower in both predator treatments than in the no-predator treatment (Tukey's post hoc test: both $P<0.001$ ) but the two predator treatments did not differ from each other $(P=$ $0.28)$. Survival rates were $2.5-4.3$ times greater in the nopredator treatment than in the predator treatments. All predators survived the experiment, suggesting that abiotic conditions were adequate to maintain L. intacta larvae (e.g., $\mathrm{O}_{2}$ requirements for Anax and fish are greater than for the smaller, less active L. intacta).

We found no difference in mean larval head width for cages in different experimental treatments at either measuring time (27 August, $F_{2,40}=0.77, P=0.47 ; 29$ September, $\left.F_{2,17}=1.44, P=0.265\right)$. We also found no evidence of compensatory growth among surviving larvae in response to mortality of conspecifics within their cages. There was no difference in the mean head width of larvae in cages with 1,2, or 3 surviving larvae at either time point in the experiment (27 August, $F_{2,39}=$ $2.53, P=0.09$; 29 September, $\left.F_{2,17}=0.19, P=0.825\right)$.

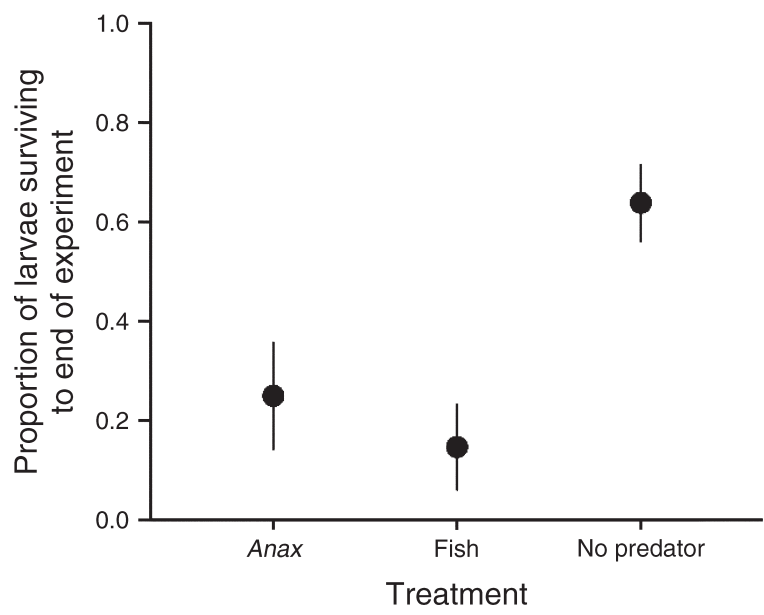

FIG. 1. Proportion of larvae of the dragonfly Leucorrhinia intacta surviving to the end of Experiment 1. Larvae were reared in cages inside aquaria containing one of three treatments: an invertebrate predator (Anax), a fish predator, or no predator. Data are means $\pm 2 \mathrm{SE} ; n=8$ replicates per treatment.

\section{Experiment 2: Effects of predator exposure} on larval mortality, metamorphic success, and adult morphology at a low predator density

Predator treatment had a significant effect on survivorship, but neither source type (fish pond or non-fish pond) nor an interaction between source and treatment affected larval survival (GLM: Treatment, $F_{1,16}=6.96, P=0.018$; Source, $F_{1,16}=1.03, P=0.325$; Source $\times$ Treatment, $\left.F_{1,16}=2.42, P=0.14\right)$. Larval survival was $10 \%$ higher in the no-predator treatment than in the caged-fish treatment (Fig. 2A). All fish survived the experiment, again suggesting that abiotic conditions in the tanks were suitable for larvae.

All but two individuals $(0.0025 \%$ of the original number of larvae in the experiment) that survived the larval period attempted emergence to the adult stage. Among individuals attempting emergence, the rate of metamorphic failure was significantly elevated in the predator treatment $\left(t_{9.8}=-2.44, P=0.035\right)$. In the predator treatment $11 \%$ of individuals that survived the larval stage died during emergence to the adult stage, while only $2 \%$ of the larval survivors died at emergence in the fishless treatment (Fig. 2B).

Head width, thorax length, and forewing length all loaded strongly and positively on a single principal component that explained $56 \%$ of the variation in the data (loading scores for each component of this axis: head width $=0.80$, thorax length $=0.67$, forewing length $=0.77$ ), no other principal component was retained in this analysis (eigenvalues $<1$ ). Body sizes in both treatments were normally distributed (fish treatment, Shapiro-Wilk $=0.99$, df $=258, P=0.31$; no fish, Shapiro-Wilk $=0.99, \mathrm{df}=315, P=0.24)$. Predator treatment had no effect on adult size (PC1; GLM with tank nested within treatment: $F_{1,18.5}=0.87, P=0.36$ ). 

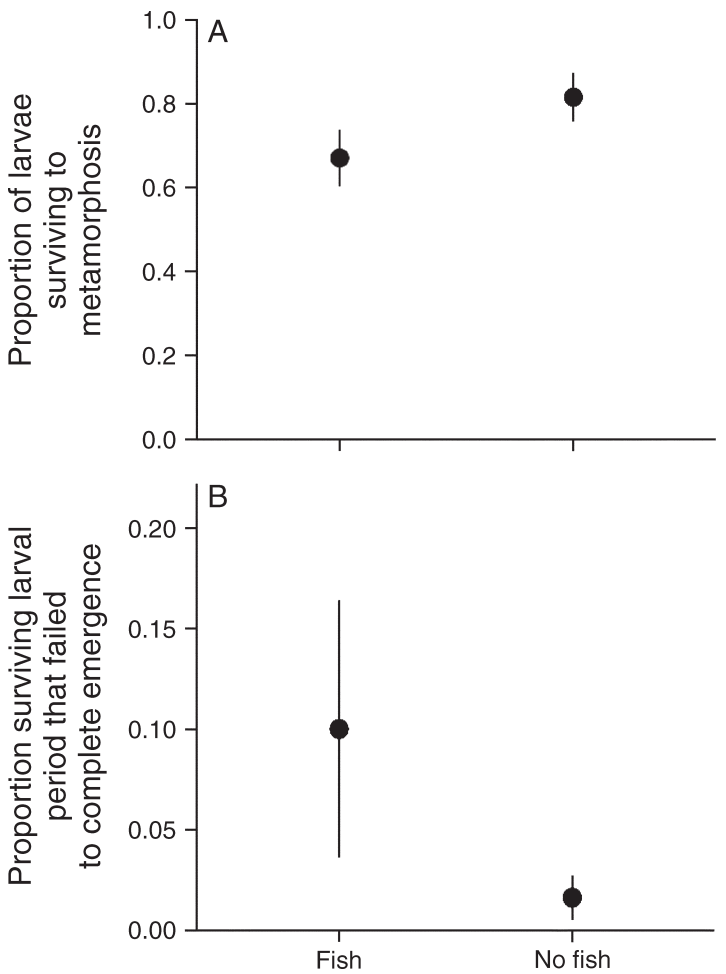

FIG. 2. Larval survivorship and metamorphic failure rates for Experiment 2. (A) Proportion of Leucorrhinia intacta larvae surviving to the point of metamorphosis. Larvae were reared in 378-L mesocosms that contained either a caged fish predator or an empty cage. Data are means $\pm 2 \mathrm{SE} ; n=40$ replicates per treatment. (B) Proportion of larvae that survived the larval stage but died during the process of metamorphosis to adult stage. Data are means $\pm 2 \mathrm{SE} ; n=10$ replicates per treatment.

This pattern was robust given that predator treatment did not affect body size even when we used a more liberal test and considered each individual as an independent data point.

\section{Discussion}

In both studies, dragonfly larvae suffered higher mortality in the presence of both fish and invertebrate predators located behind barriers that prevented predation yet allowed for sensory cues. Dragonflies reared in the presence of caged fish also exhibited higher mortality during metamorphosis to the adult stage, a time of additional stress. However, we did not detect an effect of predators on larval or adult body size in these experiments. This result suggests that either mortality in the predator treatments was greatest among larvae that had the strongest growth responses to fish, eliminating these individuals from our samples, or that these mortality effects occurred in the absence of an associated growth reduction in response to predators. The last circumstance, no growth response to fish, could occur because larval mortality in predator treatments increases the resources available for surviving larvae (Brodin and Johansson 2002). However, we did not find evidence for thinning effects, because there was no growth advantage for larvae in cages with fewer surviving larvae. Our experiments maintained zooplankton densities that allowed larvae to feed ad libitum (i.e., zooplankton were consistently abundant in containers), and this probably mitigated effects of larval competition on growth. Nonetheless even if prey were not strongly depleted, mortality among the larvae could reduce competition and lower the costs of foraging, which might affect larval condition, a factor not measured in this experiment. In future work on nonconsumptive predator effects, assessing the impact of competitor mortality on surviving prey condition may shed new light on these indirect effects.

Larval mortality levels varied between these studies: mortality increased 2.5 times in the presence of Anax junius and more than fourfold in the presence of fish in laboratory experiments, and mortality increased 1.2 times in the presence of caged fish in the mesocosm study. These differences may reflect differences in the intensity or types of cues received by larvae. The smaller size of the experimental units employed in the laboratory resulted in a higher fish density (one predator per $75 \mathrm{~L}$ compared to one fish per $378 \mathrm{~L}$ in the mesocosm study), and predators in the laboratory study were fed larval Leucorrhinia intacta, whereas in the mesocosm study predators were fed other invertebrates. Handling and ingestion of conspecific prey by predators can affect the level of risk perceived by prey (Chivers et al. 1996, Brodin et al. 2006, Schoeppner and Relyea 2009), and potentially could have influenced the magnitude of indirect mortality. In natural habitats the intensity of predator cues to which dragonfly larvae are exposed can be highly variable, but our results indicate that predatorinduced, nonconsumptive mortality can occur across a range of conditions and reach high levels when predators are dense and feeding on conspecific dragonflies.

The proximate mechanism responsible for increased mortality in the predator treatments is not known, but two factors may be important contributors: reduced net energy gains and increased vulnerability to pathogens. Reduced activity and foraging are common responses to predator cues (Benard 2004), and a small decline in activity has been observed in larval $L$. intacta exposed nonlethally to fish (McCauley 2005). This behavioral response, in combination with costs associated with induction of longer spines in the presence of fish (McCauley et al. 2008), could increase mortality from a decline in nutritional status. This hypothesis might apply to the fish experiments but probably not those involving Anax predators. In prior studies, L. intacta did not reduce activity level in the presence of Anax predators (McCauley 2005, McCauley et al. 2008). The potential influence of parasites was not examined in our present study. Larvae were collected from natural habitats, and disease might account for mortality in the no-predator treatments of both experiments, which 
ranged from $36 \%$ in laboratory Experiment 1 to $18.5 \%$ in the mesocosm experiment. Larval mortality in an environment with abundant food and lacking predators suggests a role for disease. Cannibalism also could play a role, but, as discussed below, seems unlikely to explain differences in mortality between no-predator and predator treatments in these experiments.

Stress response to the presence of predators in the immediate environment has been demonstrated in numerous animals (Hawlena and Schmitz 2010) including damselflies, a group closed related to dragonflies (Slos and Stoks 2008). Stress involves increases in stress hormones (Sheriff et al. 2009, Travers et al. 2010) and can negatively affect animals in a variety of ways, including compromised immune response (Slos and Stoks 2008, Slos et al. 2009) and altered behavioral patterns involving trade-offs that affect survival (Werner and Peacor 2003, Preisser et al. 2005, Ramirez and Snyder 2009). We did not measure neuroendocrine stress responses, however these responses are known to be common in diverse taxa (Hawlena and Schmitz 2010) with the potential to generate a cascade of negative physiological responses. Organisms under stress are often more vulnerable to a range of mortality causes that often interact synergistically. For example, mass mortality in temperate-zone fish populations during winter results from interactions among thermal stress, predators, and disease (Hurst 2007). Similarly, amphibian exposure to predator cues (Relyea 2005) can increase the lethality of an herbicide. Increased mortality among larval L. intacta in the presence of nonconsumptive predators suggests that the systemic effects of stress make larvae more vulnerable to mortality factors, including the interactive effects of reduced energy gains and exposure to pathogens that might otherwise remain sublethal. Increased metamorphic failure in the presence of caged fish also could reflect a stress response above and beyond the normal stresses associated with metamorphosis (Heyland and Moroz 2006, Menon and Roman 2007). We know comparatively little about how stress affects invertebrates (Preisser 2009). Our results suggest that predator-induced stress can decrease metamorphic success in invertebrates with complex life cycles.

An additional mortality source, cannibalism, is common in larval odonates, but three observations suggest that cannibalism is not responsible for the increased mortality observed in the predator treatments. First, cannibalism could not explain all of the mortality in the laboratory experiments in which larvae were caged in groups of three and all three individuals died. This occurred in 34\% of the Anax-treatment cages, and $65 \%$ of the fish-treatment cages, but was rare in the nopredator treatments $(3 \%)$. Second, as mentioned previously, exposure to predators is often associated with decreased activity (Preisser et al. 2005), as demonstrated for L. intacta (McCauley 2005). Decreased movement by larvae exposed to a predator would decrease larval encounter rates, which would be expected to decrease rather than increase rates of cannibalism. Finally, cannibalism clearly plays no role in metamorphic failure, one of the key differences observed between the fish-present and no-predator treatments in the mesocosm experiment.

Nonconsumptive, predator-induced mortality has important implications for understanding predator-prey dynamics and food-web structure. While this source of mortality would directly and negatively affect prey populations, it would not necessarily have a positive influence on predator populations. Instead, mortality induced by the mere presence of a predator likely would channel more resources to scavengers or decomposers. Many aquatic insects have complex life cycles and their emergent adults transfer aquatic production to riparian terrestrial systems (e.g., Wesner 2010), therefore nonconsumptive, predator-induced mortality would decrease this flow of energy and material. Decreased immunity and increased infection rates under predatorinduced stress could influence mortality (Ramirez and Snyder 2009). Mortality might represent a diffuse form of indirect negative interaction that influences prey availability numerous for predators in a food web.

Our experimental results revealed greater mortality of dragonflies during metamorphosis that was caused by prior exposure to predators during the larval stage. The extent to which predator-induced, nonconsumptive mortality occurs in other animals is currently unknown. Accounting for this form of mortality may aid interpretation of results from studies of predation that are focused on direct consumption. Our findings indicate that a certain amount of prey mortality can be caused by predator-induced stress, and points to the need to advance understanding of indirect effects of predators on prey populations (Sheriff et al. 2009, Preisser 2009, Beckerman et al. 2010).

\section{ACKNOWLEDGMENTS}

We thank C. Baines and S. Schneider for help in the field and J. Jensen and J. Pineau for logistical support. The Koffler Scientific Reserve and A. Weis provided outstanding facilities and research support. This study was funded by Natural Sciences and Engineering Research Council grants to L. Rowe and M.-J. Fortin. Comments from two anonymous reviewers improved this work.

\section{Literature Cited}

Beckerman, A. P., O. L. Petchey, and P. J. Morin. 2010. Adaptive foragers and community ecology: linking individuals to communities and ecosystems. Functional Ecology 24:1-6.

Benard, M. F. 2004. Predator-induced phenotypic plasticity in organisms with complex life histories. Annual Review of Ecology, Evolution, and Systematics 35:651-673.

Benard, M. F., and J. A. Fordyce. 2003. Are induced defenses costly? Consequences of predator-induced defenses in western toads, Bufo boreas. Ecology 84:68-78.

Brodin, T., and F. Johansson. 2002. Effects of predatorinduced thinning and activity changes on life history in a damselfly. Oecologia 132:316-322.

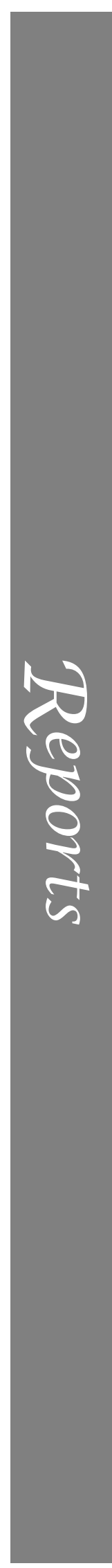


Brodin, T., D. J. Mikolajewski, and F. Johansson. 2006 Behavioural and life history effects of predator diet cues during ontogeny in damselfly larvae. Oecologia 148:162-169.

Chivers, D. P., B. D. Wisenden, and R. J. F. Smith. 1996 Damselfly larvae learn to recognize predators from chemical cues in the predator's diet. Animal Behaviour 52:315-320.

De Block, M., M. A. McPeek, and R. Stoks. 2007. Winter compensatory growth under field conditions partly offsets low energy reserves before winter in a damselfly. Oikos 116:1975-1982.

Fraker, M. E. 2009. Predation risk assessment by green frog (Rana clamitans) tadpoles through chemical cues produced by multiple prey. Behavioral Ecology and Sociobiology 63:1397-1402.

Hawlena, D., and Oswald J. Schmitz. 2010. Physiological stress as a fundamental mechanism linking predation to ecosystem functioning. American Naturalist 176:537-556.

Heyland, A., and L. L. Moroz. 2006. Signaling mechanisms underlying metamorphic transitions in animals. Integrative and Comparative Biology 46:743-759.

Hurst, T. P. 2007. Causes and consequences of winter mortality in fishes. Journal of Fish Biology 71:315-345.

Kotler, B. P., J. S. Brown, R. H. Slotow, W. L. Goodfriend, and M. Strauss. 1993. The influence of snakes on the foraging behavior of gerbils. Oikos 67:309-316.

McCauley, S. J. 2005. Species distributions in anisopteran odonates: effects of local and regional processes. Dissertation. University of Michigan, Ann Arbor, Michigan, USA.

McCauley, S. J., C. J. Davis, and E. E. Werner. 2008. Predator induction of spine length in larval Leucorrhinia intacta (Odonata). Evolutionary Ecology Research 10:435-447.

Menon, J., and R. Roman. 2007. Oxidative stress, tissue remodeling and regression during amphibian metamorphosis. Comparative Biochemistry and Physiology Part C: Toxicology and Pharmacology 145:625-631.

Preisser, E. L. 2009. The physiology of predator stress in freeranging prey. Journal of Animal Ecology 78:1103-1105.

Preisser, E. L., and D. I. Bolnick. 2008. The many faces of fear: comparing the pathways and impacts of nonconsumptive predator effects on prey populations. PLoS ONE 3(6):e2465.
Preisser, E. L., D. I. Bolnick, and M. F. Benard. 2005. Scared to death? The effects of intimidation and consumption in predator-prey interactions. Ecology 86:501-509.

Ramirez, R. A., and W. E. Snyder. 2009. Scared sick? Predatorpathogen facilitation enhances exploitation of a shared resource. Ecology 90:2832-2839.

Relyea, R. A. 2001. The lasting effects of adaptive plasticity: predator-induced tadpoles become long-legged frogs. Ecology 82:1947-1955.

Relyea, R. A. 2005. The lethal impacts of roundup and predatory stress on six species of North American tadpoles. Archives of Environmental Contamination and Toxicology 48:351-357.

Schoeppner, N. M., and R. A. Relyea. 2009. Interpreting the smells of predation: how alarm cues and kairomones induce different prey defences. Functional Ecology 23:1114-1121.

Sheriff, M. J., C. J. Krebs, and R. Boonstra. 2009. The sensitive hare: sublethal effects of predator stress on reproduction in snowshoe hares. Journal of Animal Ecology 78:1249-1258.

Slos, S., L. De Meester, and R. Stoks. 2009. Food level and sex shape predator-induced physiological stress: immune defence and antioxidant defence. Oecologia 161:461-467.

Slos, S., and R. Stoks. 2008. Predation risk induces stress proteins and reduces antioxidant defense. Functional Ecology 22:637-642.

SPSS. 2008. SPSS version 17.0.0. SPSS, Chicago, Illinois, USA.

Stamper, C. E., J. R. Downie, D. J. Stevens, and P. Monaghan. 2009. The effects of perceived predation risk on pre- and post-metamorphic phenotypes in the common frog. Journal of Zoology 277:205-213.

Stoks, R. 2001. Food stress and predator-induced stress shape developmental performance in a damselfly. Oecologia 127:222-229.

Travers, M., M. Clinchy, L. Zanette, R. Boonstra, and T. D. Williams. 2010. Indirect predator effects on clutch size and the cost of egg production. Ecology Letters 13:980-988.

Werner, E. E., and S. D. Peacor. 2003. A review of traitmediated indirect interactions in ecological communities. Ecology 84:1083-1100.

Wesner, J. S. 2010. Aquatic predation alters a terrestrial prey subsidy. Ecology 91:1435-1444. 